\title{
Molecular Modeling Study of PPAR $\gamma$ Agonists: Dehydro-Di-Isoeugenol, Macelignan, Pioglitazone, Netoglitazone, and Rosiglitazone as Antidiabetic Drugs
}

\author{
Nyi Mekar Saptarini ${ }^{1}$, Febrina Amelia Saputri ${ }^{1} \&$ Jutti Levita $^{1}$ \\ ${ }^{1}$ Faculty of Pharmacy, Padjadjaran University, West Java, Indonesia \\ Correspondence: Nyi Mekar Saptarini, Faculty of Pharmacy, Padjadjaran University, Jl. Raya \\ Bandung-Sumedang Km.21 Jatinangor Sumedang, West Java 45363, Indonesia. Tel: 62-815-607-8248. Fax: 62- \\ 227-796-200. E-mail: nyi.mekar@unpad.ac.id
}

Received: February 23, 2014 Accepted: April 2, 2014 Online Published: April 14, 2014

doi:10.5539/ijc.v6n2p48

URL: http://dx.doi.org/10.5539/ijc.v6n2p48

\begin{abstract}
The peroxisome proliferator-activated receptors (PPARs) are ligand-activated trasncription factors belonging to the nuclear receptor family. The objective of this study is to analyze the molecular aspects of PPAR $\gamma$ agonists which used to design of new antidiabetic drugs. The analysis method was comparing the interactions of ligands in the ligand binding domain of the PPAR $\gamma$. This analysis showed that most known agonists of PPAR $\gamma$ interacted via hydrogen bond with Tyr473. Pioglitazone showed three hydrogen bonds with His323 and Tyr473. Netoglitazone showed four hydrogen bonds with Ser289, His323, His449, and Tyr473. Rosiglitazone showed five hydrogen bonds with Ser289, His323, His449, and Tyr473. AZ72, an agonist of PPAR $\alpha$ and $\gamma$ showed five hydrogen bonds with Ser289, His323, His449, and Tyr473. Molecular modeling was performed by redocking pioglitazone and rosiglitazone using AutoDock Vina. Docking showed that both pioglitazone (Ki $0.22 \mu \mathrm{M})$ and rosiglitazone (Ki $0.70 \mu \mathrm{M})$ occupied their origin sites and interacted with Tyr473. Docking simulation was also performed between dehydro-di-isoeugenol and macelignan to visualize the interaction with PPAR $\gamma$. These two compounds are found in nutmeg's seed (Myristica fragrans Hout) that have been proven had antidiabetic activity in vitro. It can be concluded that agonists of PPAR $\gamma$ should have hydrogen bond donor and acceptor groups for interacting with Tyr473. Tyr473 might be a critical site of interaction between the PPAR $\gamma$ ligand binding domain and its agonists.
\end{abstract}

Keywords: dehydro-di-isoeugenol, docking simulation, macelignan, netoglitazone, PPAR $\gamma$, pioglitazone, rosiglitazon

\section{Introduction}

Diabetes mellitus (DM) is a group of clinical and genetic disorder that characterized by increasing levels of glucose in the blood. Among the various types of DM, more than $95 \%$ of people with diabetes is type 2 diabetes mellitus (T2DM) (American Diabets Association, 2009). T2DM is a combination of insulin resistance and pancreatic $\beta$ cell insufficiency. One of the receptors target for the treatment of T2DM is peroxisome proliferator-activated receptor $\gamma(\operatorname{PPAR} \gamma)$.

The peroxisome proliferator-activated receptors (PPARs) $\gamma, \beta$, and $\alpha$ compose a nuclear receptor subfamily that modulates the transcription of a large compendium of genes encoding proteins that regulate lipid metabolism, cell differentiation, and signal transduction in a ligand-dependent manner. PPARs bind as heterodimers with a retinoid $\mathrm{X}$ receptor and, upon binding agonist, interact with cofactors so the rate of transcription initiation is increased. The PPARs play a critical physiological role as lipid sensors and regulators of lipid metabolism (Berger \& Moller, 2002). PPAR $\gamma$ has been shown to be a master regulator of adipogenesis and nutrient metabolism in adipocytes where it is highly expressed. PPARs are activated by fatty acids and eicosanoids, which have been identified as natural ligands for the PPARs, hence these receptors are targets for antidyslipidemic drugs and of antidiabetic agents (Cronet et al., 2001; Berger \& Moller, 2002). More potent synthetic PPAR ligands, including the fibrates and thiazolidinediones (TZDs), have proven effective in the treatment of dyslipidemia and diabetes (Berger \& Moller, 2002). TZDs or glitazones, a class of antidiabetic agents, have been reported as high affinity agonists of PPAR $\gamma$ (Willson et al., 2000). 
TZDs were acted as insulin sensitizers. These compounds improve insulin resistance by increasing cell sensitivity to insulin. PPAR $\gamma$ agonists increase peripheral insulin sensitivity by increasing the transcription of genes, which, in turn, increase glucose uptake, also improving insulin-stimulated glucose disposal in muscle. $\operatorname{PPAR} \gamma$ agonists also increase insulin signaling, reduce circulating levels of free fatty acids and stimulate adipocyte differentiation, thus favoring the formation of smaller, more insulin-sensitive adipocytes. TZDs have been proven effective in different experimental models to evaluate their effectiveness as an antidiabetic agent. There were excellent correlation between the hypoglycemic action of TZDs and their affinity for PPAR $\gamma$ (Vazquez et al., 2002). TZDs produce a conformational change in PPAR analogous to those produced by agonists of other nuclear hormone receptors. Antidiabetic actions of TZDs are directly mediated through binding to PPAR $\gamma$ and the resulting active conformation of the receptor. Therefore, binding and transactivation assays using PPAR $\gamma$ should serve to identify other novel therapeutic agents with potential antidiabetic activities (Berger et al., 1996).

Macelignan that had been isolated from nutmeg's seed (Myristica fragrans Hout) can activate the PPAR $\gamma$ (Han et al., 2008). Other studies indicate that macelignan not clearly detected in extracts of nutmeg because its concentration is very small. Based on screening of chemical compounds in nutmeg extracts and in vitro test with GAL-4/PPAR chimera assay and reported gene method, dehydro-di-isoeugenolhas proved can activate PPAR $\gamma$ (Lestari, 2010). This study is aimed to study the molecular aspects of PPAR $\gamma$ agonists' binding mode by comparing the interactions of ligands that were co-crystalized in the ligand binding domain of PPAR $\gamma$ for antidiabetic drug design.

\section{Method}

\subsection{Materials}

Personal computer with Mobile Dual Core Intel Core 2 Duo T7250, 1978 MHz (10 x 198) (www.intel.com), hard disk $250 \mathrm{~GB}$, graphic ATI Mobility Radeon HD 3400 Series (256 MB) and system memory $2044 \mathrm{MB}$ (DDR2 - 667 DDR2 SDRAM). Softwares used in this study were Jmol Viewer version 12.2.15 and RSCB PDB Ligand Explorer Viewer 3.9 (powered by the MBT) that are embedded in http://www.pdb.org/, and Q-SiteFinder (http://bmbpcu36.leeds.ac.uk/qsitefinder/help.html).

\subsection{Macromolecule Preparation and Molecular Modeling}

3D structures of PPAR $\gamma$ crystallized using X-ray diffraction (code: 2XKW, 1FM6, 3B0Q, 1I7I, 3B0R, 3AN3) were downloaded from online Protein Data Bank (http://www.pdb.org) and viewed by using Jmol Viewer version 12.2.15. Ligand interactions were analyzed by using RSCB PDB Ligand Explorer Viewer 3.9 (powered by the MBT). The chain A of the protein and its co-crystallized inhibitors were separated by using SwissPDBViewer version 4.01 (http://www.expasy. org). The volume and position of PPAR $\gamma$ 's binding site was calculated and located by using Q-SiteFinder. Q-SiteFinder was also used to predict amino acid residues in the ligand binding domain of PPAR $\gamma$. Molecular docking was performed by using AutoDock Vina (Molecular Graphics Laboratory, The Scripps Research Institute, http://vina.scripps.edu/download.html).

\section{Results and Discussion}

PPAR $\gamma$ ligand binding domain contains amino acid residues 204 to 477 . The volume of the binding domain calculated by Q-SiteFinder is 864 cubic angstroms. Six agonists that has been co-crystallized in the ligand binding domain of PPAR $\gamma$ selected from Protein Data Bank (http://www.pdb.org), were extracted and redocked into their origin place in the PPAR $\gamma$ binding domain. The results were showed in Figure 1. 


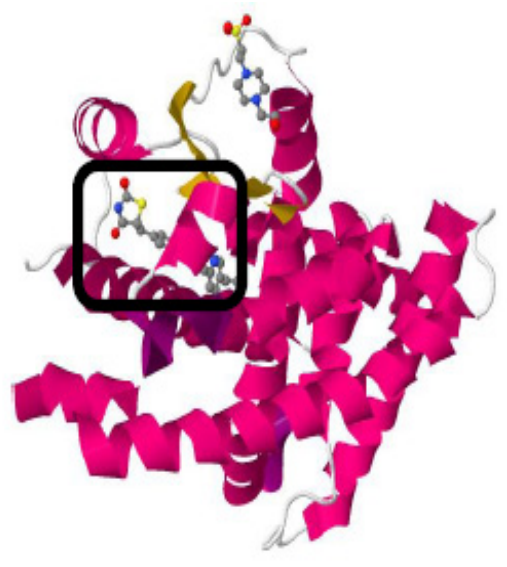

(a)

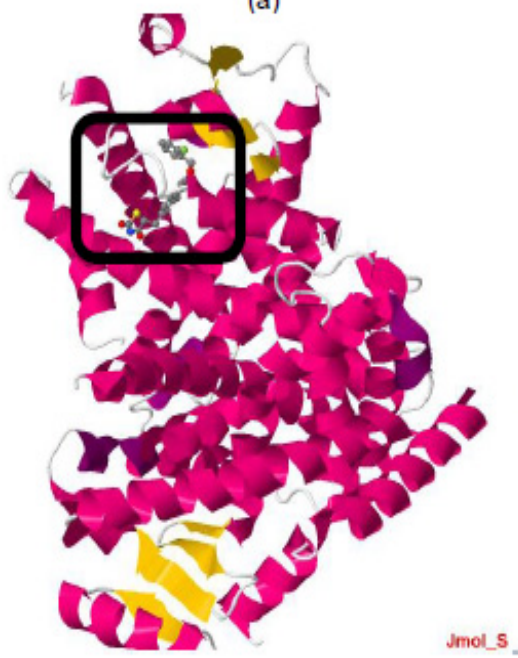

(c)

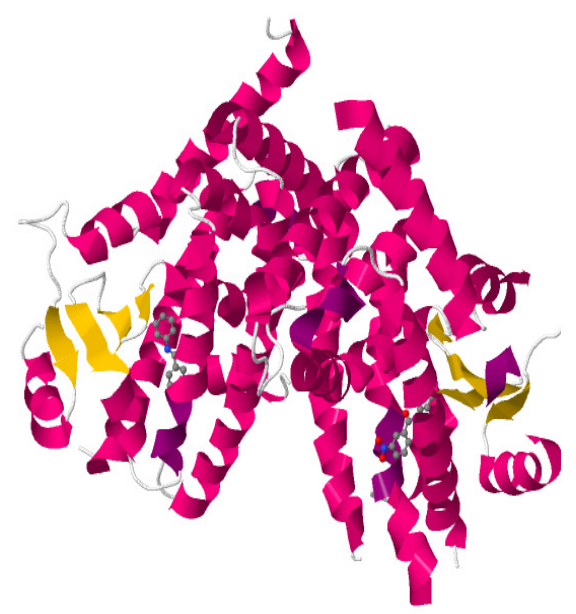

(e)

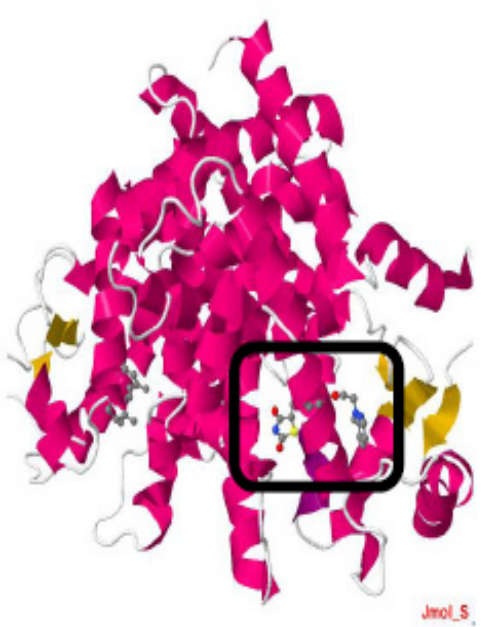

(b)

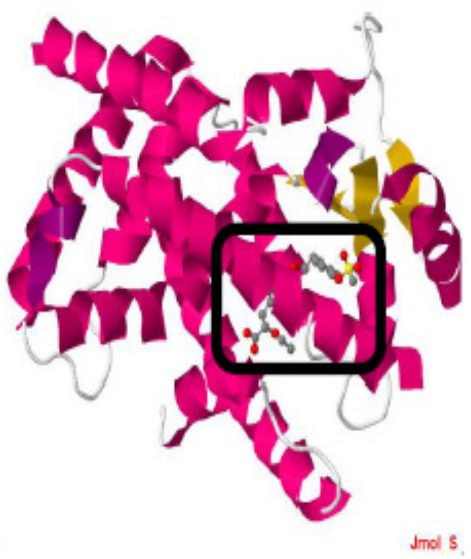

(d)

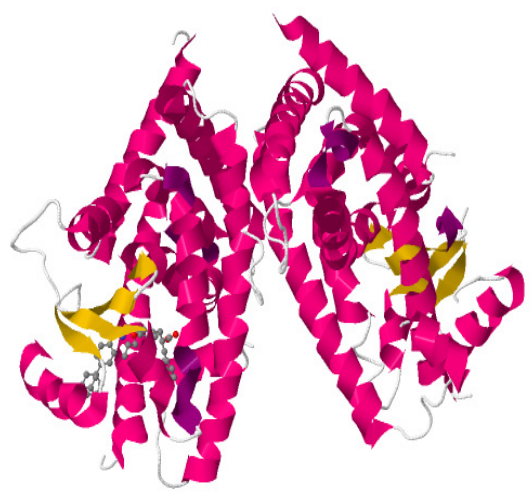

(f)

Jmol_S

Figure 1. 3D structure of PPAR $\gamma$ homodimer co-crystallized with its partial agonists (a) pioglitazone (code: 2XKW); (b) rosiglitazone (code: 1FM6); (c) netoglitazone (code: 3B0Q); (d) AZ72 (code: 1I7I); (e) GW9662 (code: 3B0R); (f) MO3S (code: 3AN3) viewed by using Jmol Viewer version 12.2.15. These macromolecules were downloaded from http://www.pdb.org/ 
All of these ligands, except the benzophenilpropionic acid derivate, interacted via hydrogen bond formation with Tyr473 located within helix 12 of the ligand binding domain. Pioglitazone showed three hydrogen bonds: His 323 $(2.56 \AA)$ and Tyr473 (2.36 and $3.16 \AA)$. Netoglitazone showed four hydrogen bonds: Ser289 (26.5 $)$ ), His323 $(2.68 \AA)$, His449 (2.72 $\AA$ ), and Tyr473 (2.84 $\AA$ ). Rosiglitazone showed five hydrogen bonds: Ser289 (2.95 $\AA$ ), His323 (2.66 $\AA)$, His449 (2.84 $\AA$ ), and Tyr473 (2.82 and $3.21 \AA)$. Nitrogen and oxygen atoms of TZD's thiazolidine ring plays important role in this interaction (Figure 1a, $\mathrm{b}$, and $\mathrm{c}$ ).

AZ72, $\mathrm{C}_{20} \mathrm{H}_{24} \mathrm{O}_{7} \mathrm{~S}$, an agonist of PPAR $\alpha$ and $\gamma$ showed five hydrogen bonds: Ser289 (2.81 $\AA$ ), His323 (2.78 $\AA$ ), His449 (2.73 and $3.23 \AA$ ), and Tyr473 (2.70 $\AA$ ) (Figure 1d). The carboxylic group in this propanoic derivate shows its role as hydrogen bond donor and acceptor. GW9662, $\mathrm{C}_{13} \mathrm{H}_{9} \mathrm{ClN}_{2} \mathrm{O}_{3}$, showed four hydrogen bonds: Cys285 (2.90 $\AA)$, Tyr327 (3.04 $\AA)$, His449 (2.85 $\AA$ ), and Tyr473 (2.28 $)$. The oxygens of the nitro and carbonyl groups of the molecule interacts as hydrogen bond acceptors. MO3S, $\mathrm{C}_{37} \mathrm{H}_{43} \mathrm{NO}_{4}$, a benzophenylpropanoic acid derivate, showed interesting result in hydrogen bond formation. This ligand did not show interaction with Tyr473, but with Ser289 (2.74 $\AA$ ) and Tyr327 (2.46 $\AA$ ) instead. It was concluded that this compound showed a reversal of stereochemistry-transactivation activity (Tomioka, 2011).

Ligand preparation for dehydro-di-isoeugenol and macelignan begins with the design of $2 \mathrm{D}$ structure, then converted into a 3D structure by using ChemDraw Ultra v8.0.3 and Chem3D Ultra v8.0.3 in Chemoffice 2004 program. 3D structure then optimized geometrically to obtain the most stable conformation. Conformational changes before and after optimization shown in Figure 2. The next step is the analysis of the ligand properties using Portable HyperChem Release 8.0.7. The results of the analysis are displayed in Table 1.

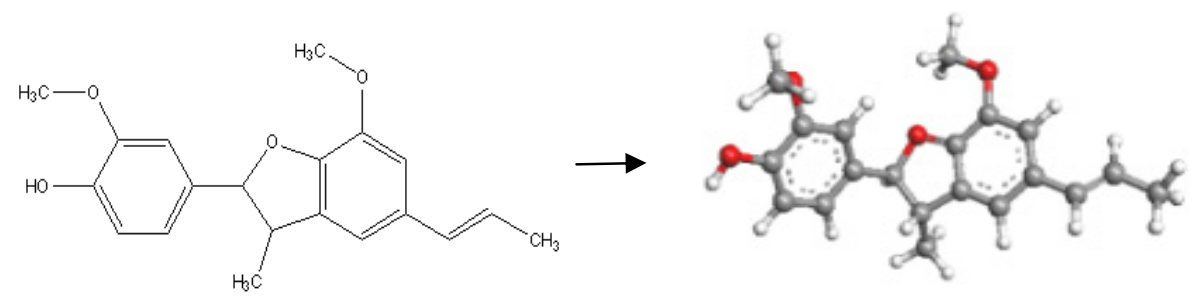

(a)
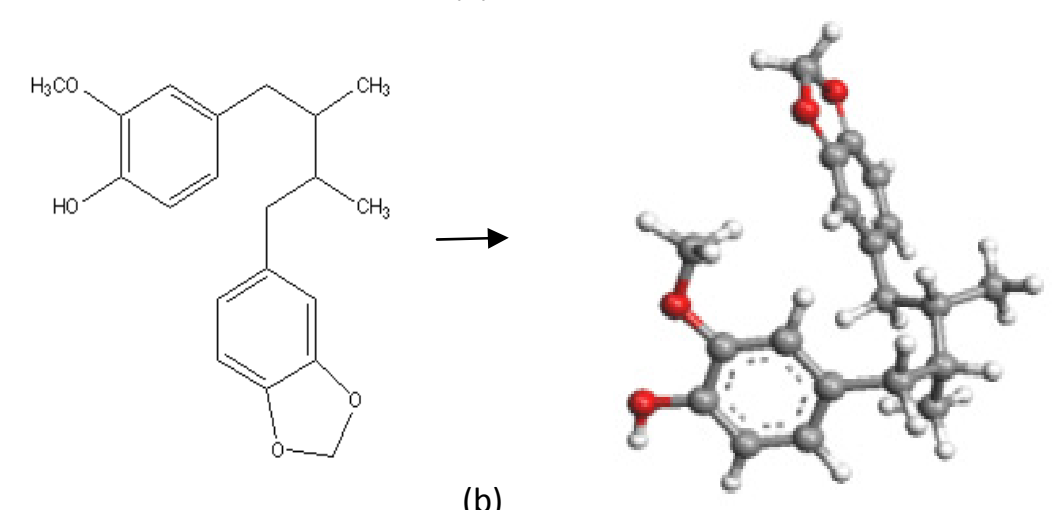

(b)

Figure 2. The results of geometry optimization (a) dehydro-di-isoeugenol, (b) macelignan

Table 1. Analysis of dehydro-di-isoeugenol, macelignan, pioglitazone, and rosiglitazon properties

\begin{tabular}{lllll}
\hline Compound & $\begin{array}{l}\text { Energy } \\
\left({\mathrm{kcal} . \mathrm{mol}^{-1}}^{-}\right)\end{array}$ & Volume $\left(\AA^{3}\right)$ & Mass (amu) & Log P \\
\hline Dehydro-di-isoeugenol & -4897.40 & 982.52 & 326.39 & -0.57 \\
Macelignan & -5026.97 & 954.26 & 328.41 & 0.64 \\
Pioglitazone & -4821.54 & 1040.99 & 356.44 & 1.63 \\
Rosiglitazone & -4679.04 & 1003.71 & 357.43 & 0.55 \\
\hline
\end{tabular}


By using the principle of Lipinski's Rule of Five as a reference, the mass of which is owned by dehydro-di-isoeugenol, macelignan, pioglitazone, and rosiglitazone meet the criteria, i.e. 326.39 amu, 328.41 amu, $356.44 \mathrm{amu}$ and $357.43 \mathrm{amu}$. Partition coefficient indicate drug solubility. The negative sign indicates that the compound is hydrophilic, whereas a positive sign indicates that the compound is lipophilic. Other properties that are used to assess the feasibility of oral route of drug compounds based on Lipinski's Rule of Five is the number of hydrogen bond donor and acceptor. Hydrogen bond donor and acceptor provide the ability to interact with the binding site of PPAR $\gamma$. Both dehydro-di-isoeugenol and macelignan have one hydrogen bond donor and four hydrogen bond acceptors (Table 2).

Table 2. The number of hydrogen bond donor and acceptor

\begin{tabular}{llll}
\hline Compound & $\begin{array}{l}\text { Hydrogen } \\
\text { donor }\end{array}$ & bond & $\begin{array}{l}\text { Hydrogen } \\
\text { acceptor }\end{array}$ \\
\hline Dehydro-di-isoeugenol & 1 & 4 \\
Macelignan & 1 & 4 & \\
Pioglitazone & 1 & 6 \\
Rosiglitazone & 1 & 7 & \\
\hline
\end{tabular}

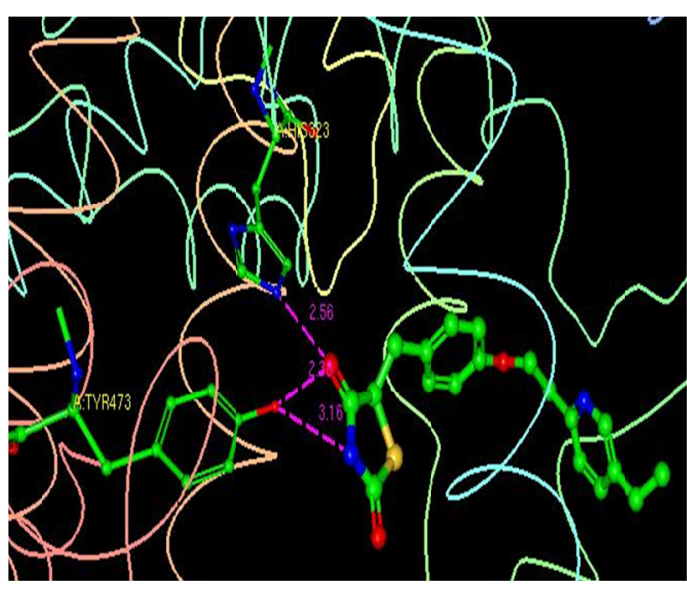

(a)

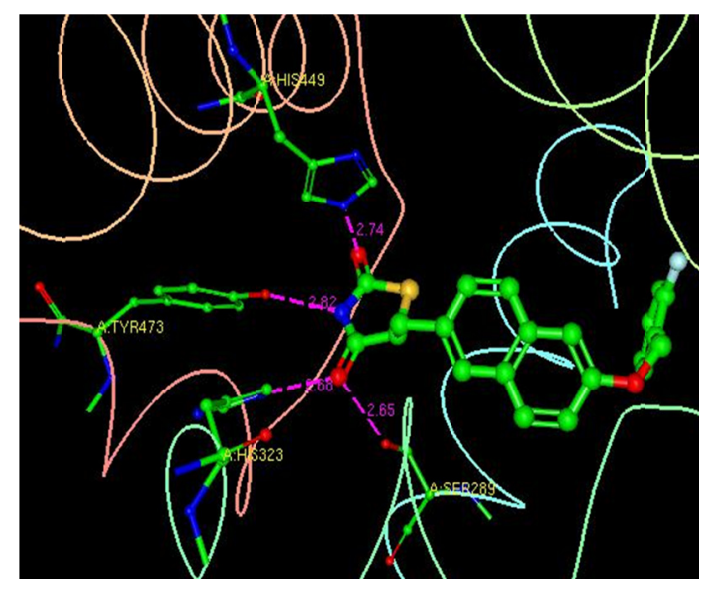

(c)

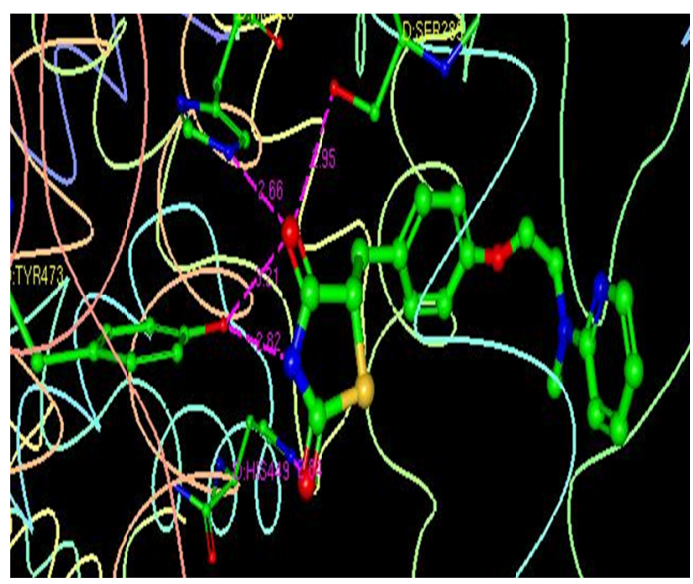

(b)

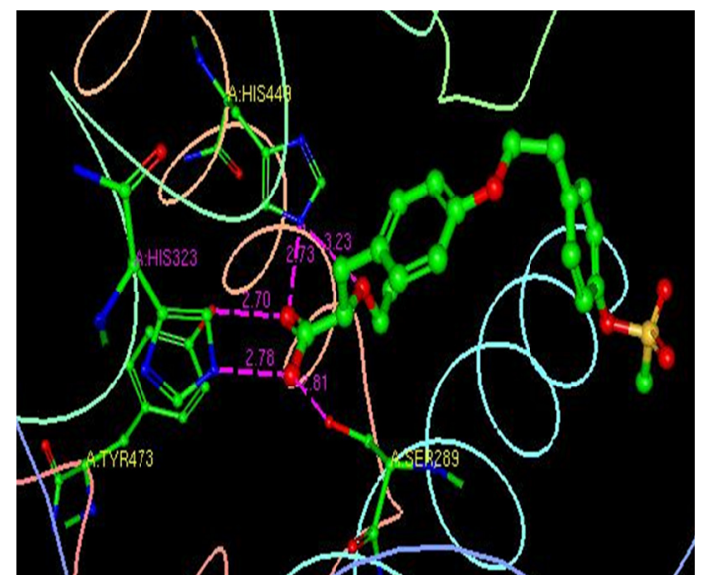

(d) 


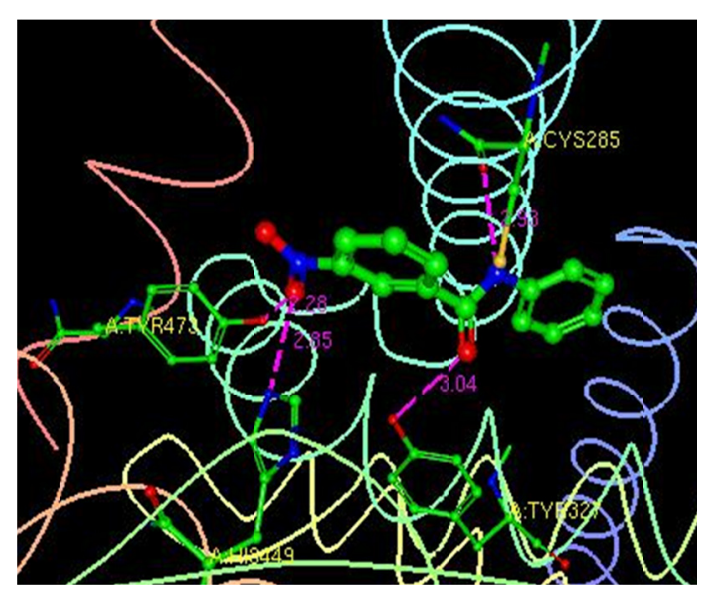

(e)

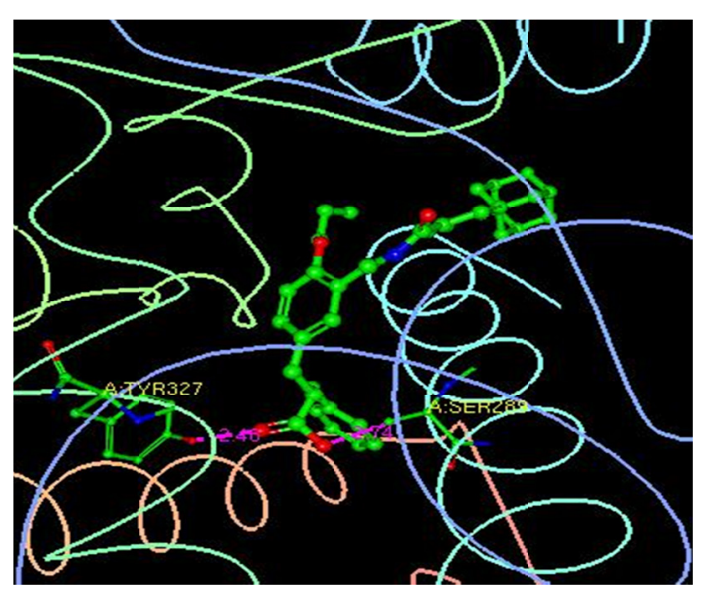

(f)

Figure 3. Ligand interaction of (a) pioglitazone (code: 2XKW); (b) rosiglitazone (code 1FM6); (c) netoglitazone (code: 3B0Q); (d)AZ72 (code: 1I7I); (e) GW9662 (code: 3B0R); (f) MO3S (code: 3AN3) in the binding domain of PPAR $\gamma$ viewed by using RSCB PDB Ligand Explorer Viewer 3.9 (powered by the MBT). Hydrogen bonds were showed by magenta dashes

Redocking pioglitazone and rosiglitazone into their origin place in the PPAR $\gamma$ binding domain confirmed that these ligands interacted with similar binding mode (Figure 4). Both ligands interacted with Tyr473 residue in the ligand binding domain of PPAR $\gamma$.

Pioglitazone interacted with Tyr473 via the formation of two hydrogen bonds, while rosiglitazone only formed one hydrogen bond. The interaction energy and inhibition constant value (Ki) of pioglitazone were -10.32 $\mathrm{kcal} / \mathrm{mol}$ and $0.22 \mu \mathrm{M}$; while those of rosiglitazone were $-9.69 \mathrm{kcal} / \mathrm{mol}$ and $0.70 \mu \mathrm{M}$, respectively. Dehydro-di-isoeugenol's were $-9.30 \mathrm{kcal} / \mathrm{mol}$ and $0.72 \mu \mathrm{M}$, while macelignan's were $-8.67 \mathrm{kcal} / \mathrm{mol}$ and 2.41 $\mu \mathrm{M}$, respectively. Value of $\mathrm{Ki}$ indicates ligand's affinity to the receptor, where the smaller value of $\mathrm{Ki}$, the more easy for ligand to bind to the receptor. Based on the interaction energy and Ki values, dehydro-di-isoeugenol and macelignan could be developed as oral antidiabetic drugs, but due to their weaker affinity compared to pioglitazone and rosiglitazone, we suggested to modify their molecular structures to obtain better antidiabetic activity. 


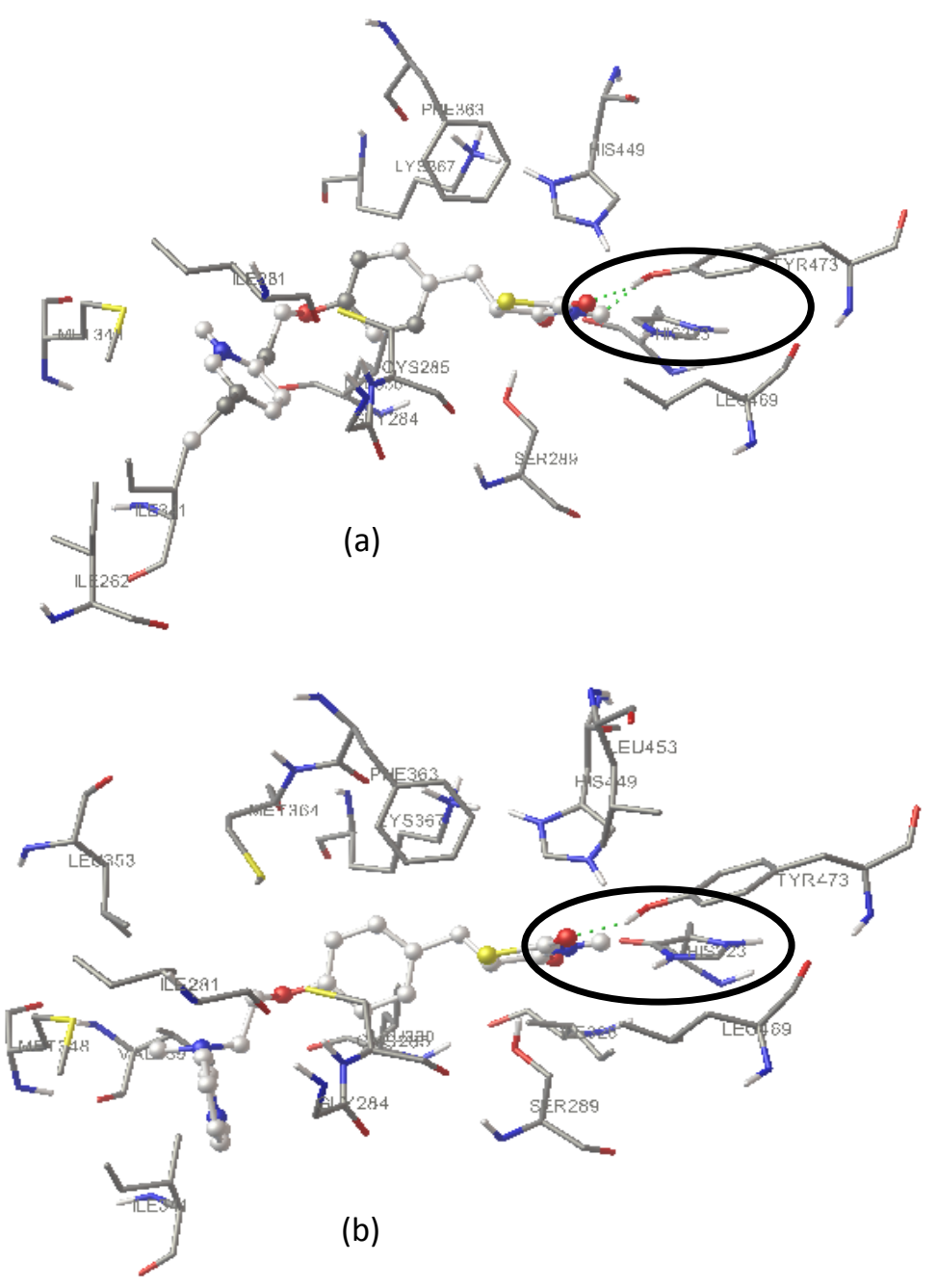

Figure 4. Molecular docking of (a) pioglitazone and (b) rosiglitazone with PPAR $\gamma$. Hydrogen bond interactions of the ligands with Tyr473 were showed by black ovals

\section{Conclusion}

- Agonists of PPAR $\gamma$ should have hydrogen bond donor and acceptor for interacting with Tyr473 residue in the ligand binding domain of the receptor. Nitrogen and oxygen atoms of TZD's thiazolidine ring plays important role in this interaction. Tyr473 might be a critical site of interaction between PPAR $\gamma$ ligand binding domain and TZD derivates.

- Agonists of PPAR $\gamma$ with benzophenylpropanoic acid system interacted with Tyr327 instead of Tyr473. This phenomena confirmed a reversal of stereochemistry-transactivation activity of these class of compounds.

- Dehydro-di-isoeugenol and macelignan potentially can be developed into an oral antidiabetic drug because the value of energy interaction and inhibition constant are still relatively close to pioglitazone.

\section{References}

American Diabetes Association. (2009). Diagnosis and Classification of Diabetes Mellitus. Diabetes Care, 32(Suppl. 1), S62-S67. http://dx.doi.org/10.2337/dc09-S062

Berger, J. (2005). Role of PPAR $\gamma$, transcriptional cofactors, and adiponectin in the regulation of nutrient metabolism, adipogenesis and insulin action: view from the chair. International Journal of Obesity, 29, S3-S4. http://dx.doi.org/10.1038/sj.ijo.0802904

Berger, J., \& Moller, D. E. (2002). The Mechanisms of Action of PPARs. Annual Review of Medicine, 53. $\mathrm{http}: / / \mathrm{dx}$. doi.org/10.1146/annurev.med.53.082901.104018

Berger, J., Bailey, P., Biswas, C., Cullinan, C. A., Doebber, T. W., Hayes, N. S., ... Leibowitz, M. D. (1996). 
Thiazolidinediones Produce a Conformational Change in Peroxisomal Proliferator-Activated Receptor-gamma: Binding and Activation Correlate with Antidiabetic Actions in db/db Mice. Endocrinology, 137(10). http://dx.doi.org/10.1210/en.137.10.4189

Cronet, P., Petersen, J. F., Folmer, R., Blomberg, N., Sjöblom, K., Karlsson, U., ... Bamberg, K. (2001). Structure of the PPARalpha and -gamma ligand binding domain in complex with AZ 242; ligand selectivity and agonist activation in the PPAR family. Structure, 9(8). http://dx.doi.org/10.1152/ajpendo.00269.2012

Gampe Jr., R. T., Montana, V. G., Lambert, M. H., Miller, A. B., Bledsoe, R. K., Milburn, M. V., ... Xu, H. E. (2000). Asymmetry in the PPAR/RXR crystal structure reveals the molecular basis of heterodimerization among nuclear receptors. Mol. Cell., 5. http://dx.doi.org/10.2210/pdb1fm6/pdb

Han, K. L., Joo, S. C., Young, J. L., Jihyun, S., Myung, K. K., Myeong, H. J., \& Hwang, J. K. (2008). Therapeutic Potential of Peroxisome proliferator-activated reseptor $\gamma$ in 3T30L1 adipocytes. Biol. Pham. Bull., 29, 110-3. http://dx.doi.org/10.1248/bpb.29.110

Lestari, K. (2010). Ringkasan Disertasi Pengembangan Biji Pala (Myristica fragrans Hout) sebagai Antihiperlipidemik dan Antidislipidemik dengan Efek Agonis Ganda pada PPAR $\gamma$. Universitas Padjadjaran. Bandung.

Mueller, J. J., Schupp, M., Unger, T., Kintscher, U., \& Heinemann, U. (2011). Binding Diversity of Pioglitazone by Peroxisome Proliferator-Activated Receptor-Gamma. http://dx.doi.org/10.2210/pdb2xkw/pdb

Murphy, G. J., \& Holder, J. C. (2000). PPAR-gamma agonists: Therapeutic role in diabetes, inflammation and cancer. Trends Pharmacol. Sci., 24(12).

Ohashi, M., Oyama, T., Nakagome, I., Satoh, M., Nishio, Y., Nobusada, H., ... Miyachi, H. (2011). Design, Synthesis, and Structural Analysis of Phenylpropanoic Acid-type PPAR $\gamma$-Selective Agonists: Discovery of Reversed Stereochemistry-Activity Relationship. J. Med. Chem., 54, 331-341. http://dx.doi.org/10.1021/jm101233f

Rogler, G. (2006). Significance of Antiinflammatory Effects of PPAR $\gamma$ Agonists. Gut, 55, $1067-1069$. http://dx.doi.org/10.1136/gut.2005.089946

Shimizu, T. (2012). Human PPAR-gamma Ligand Binding Domain Complexed with GW9662 in a Covalent Bonded Form. http://dx.doi.org/10.2210/pdb3b0r/pdb

Tomioka, D., Hashimoto, H., Sato, M., \& Shimizu, T. (2011). Human PPAR gamma ligand binding domain in complex with MCC555. http://dx.doi.org/10.2210/pdb3b0q/pdb

Vázquez, M., Silvestre, J. S., \& Prous, J. R. (2002). Experimental approaches to study PPAR gamma agonists as antidiabetic drugs. Methods Find Clin. Pharmacol., 24(8). http://dx.doi.org/10.1358/mf.2002.24.8.705072

Wilson, T. M., Brown, P. J., Sternbach, D. D., \& Henke, B. R. (2000). The PPARs: From orphan receptors to drug discovery. J. Med. Chem., 43(4), 527-50. http://dx.doi.org/10.1021/jm990554g

\section{Copyrights}

Copyright for this article is retained by the author(s), with first publication rights granted to the journal.

This is an open-access article distributed under the terms and conditions of the Creative Commons Attribution license (http://creativecommons.org/licenses/by/3.0/). 